\title{
Control of Yeast Fermentation Bioreactor in Subspace
}

\author{
Seshu Kumar Damarla \\ Department of Chemical Engineering \\ National Institute of Technology Rourkela, India
}

\author{
Madhusree Kundu \\ Department of Chemical Engineering \\ National Institute of Technology Rourkela, India
}

\begin{abstract}
PCA based temperature controller was used to control Ethanol concentration produced in Yeast fermentation process. The controller was designed at a specific operating point and its disturbance rejection performances were studied. Substrate inlet temperature proved to be the most significant disturbance input from the analysis of open loop responses. $Q$-statistic (SPE) of process measurements confirmed that in the face of disturbances and noise the process could be held to the specific operating condition using the controller designed in subspace.
\end{abstract}

\section{General Terms}

Statistical Process Control

\section{Keywords}

Principal Component Analysis, bioreactor, subspace

\section{INTRODUCTION}

Nonlinear and dynamic processes are posing challenges in control system design. Yeast fermentation is such a process that suffers very much from multivariable interactions, changeable parameters, effect of unknown disturbances, etc. Accomplishing optimum conditions such as $\mathrm{pH}$, temperature, agitation speed and dissolved oxygen concentration etc in bioreactor is complex task. For handling input multiplicities in bioreactor, Reddy \& Chidambaram (1994) and Jyothi \& Chidambaram (2001) have designed nonlinear proportional integral (PI) and nonlinear feed forward controller from Hammerstein model [1 \& 2]. Radhakrishnan et al. (1999) proposed nonlinear self tuning controller approach that updates controller parameters based on nonlinear auto regressive moving average with exogenous inputs (NARMX) model [3]. Linear controller which is designed at one operating condition may not perform well when operating point changes. Generalized predictive controller and fuzzy logic based controllers have performed well in case of unstable operating conditions [ 4 \& 5]. Many advanced control laws were implemented on nonlinear fermentation process and exhibited good performance in comparison to conventional controllers [6]. Artificial Neural Networks (ANN) have been applied in modeling and control of linear and nonlinear processes. Application of advance model based controller such as Model Predictive, ANN based Model Predictive Controller, etc on bioprocess is promising approach [7-9].

In the literature cited above, it is noticeable that process model is prerequisite in the design of conventional and advanced controllers. Not only process model but also process data is equally important for monitoring and control. Modernized plants and data acquisition systems are assisting the collection of measurements of large number of process variables for every few minutes (or less). This data usually presents in huge number of dimensions and contains valuable information about normal and anomalous behavior of process.
Principal Component Analysis (PCA) is popular multivariate statistical technique used to describe original process data in low dimension space (subspace). There is strong correlation exists among these variables. Some variables do not vary (or vary to very small extent) but some are changing together. So the dimension of actual region in which process changes is lesser than the dimension of measured process variables. PCA defines the actual region as subspace by removing dimensions along which data has minimum or zero variation. Besides data dimensionality reduction, PCA can be employed for outlier detection and feature extraction [10 \& 11]. PCA facilitated the analysis of finding significant input among set of inputs of gas mixing chamber in Copper Smelter Plant that led to determination of SISO model which describes the actual MISO system [12]. PCA based MVSPC techniques; Hotelling's $T^{2}$ and Squared Prediction Error (SPE) provide the information regarding the status of current process operation which is useful for taking necessary action [13]. PCA was first applied on continuous process for monitoring purpose and later its application was extended for batch processes [14 \&15]. MVSPC methods have undergone many amendments and advances for real time monitoring.

Few attempts were made towards application of MVSPC methods in control aspects. Piovoso et al. (1992a, 1994b) formulated a controller that operates process in subspace by computing manipulated actions using generated subspace error i.e. difference between score set-points and current scores [16 \& 17]. The same concept combined with Model Predictive Controller was applied on industrial processes; Distillation column, Tennessee Eastman and Maize drying [18 $\&$ 19]. This approach is very useful when some of quality variables are not available for on-line measurement. Later Palma et al. $(2010,2011)$ incorporated a gain in the same controller formulation for effective set-point tracking [20 \& 21]. Shah et al. (1998) proposed similar kind of control structure which uses least squares technique to calculate control moves that minimize sum of squares of errors between score set-points and current scores [22]. For implementation of PCA based controller on any process, SPE of current process operation must be below its threshold. This indicates that current process region is similar to nominal operating region at which controller gets designed. To fulfill control objectives in alpha-olefins production plant, canonical variate analysis algorithm was employed by Akamatsu et al. (2000) for identification of state space model in subspace and that was used for design of feedback and feed forward controllers [23]. In this work, PCA based temperature controller has been developed that resembles proportional controller. This controller tries to reduce variance in product quality by maintaining process operation in subspace defined by PCA model. The PCA model is determined from data collected under desired operating condition. To assess the performance of the proposed controller, simulated yeast fermentation bioreactor was considered. 


\section{THEORETICAL POSTULATIONS}

\subsection{Principal Component Analysis}

Raw data matrix, $X^{n \times m}$, is consisting of $n$ measurements of $m$ process variables. PCA decomposition of the data matrix is described in Fig. 1. Usually process variables are in different magnitudes, thus it is important to auto-scale the raw data so as to have all variables in one range.

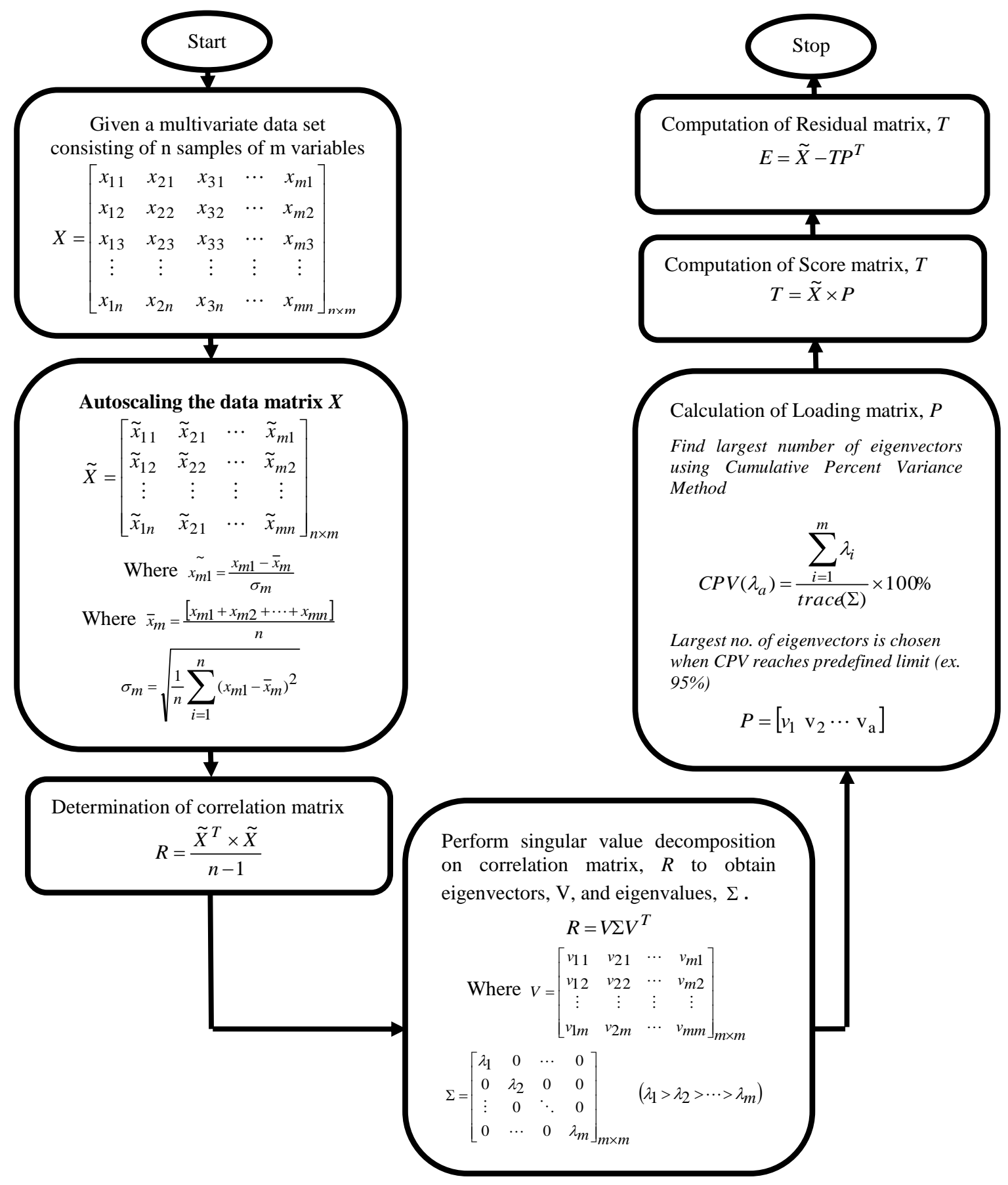

Fig 1: Principal Component Analysis

\subsection{Squared Prediction Error and Threshold}

Squared prediction error, $Q$, finds variation that has not captured by PCA model. $Q$-statistic of process measurements can be determined by moving current process operation to subspace. This will be accomplished by projecting new measurement vector onto PCA model. The corresponding scores and residual vectors can be calculated using the following equations.

$t_{\text {new }}=x_{\text {new }} P\left(P^{T} P\right)^{-1}$ 
$e_{\text {new }}=x_{\text {new }}-t_{\text {new }} P^{T}$

$Q$-statistic is defined below as sum of squares of residuals. Equation (4) gives an expression for upper limit of $Q$. If $Q$ statistic of new process measurements is greater than its threshold, current process operation region is deviated from steady state or normal operation region.

$Q=e_{\text {new }} e_{\text {new }}^{T}$

$Q_{\alpha}=\theta_{1}\left[\frac{h_{0} C_{\alpha} \sqrt{2 \theta_{2}}}{\theta_{1}}+1+\frac{\theta_{2} h_{0}\left(h_{0}-1\right)}{\theta_{1}{ }^{2}}\right]^{\frac{1}{h_{0}}}$

Where, $\theta_{i}=\sum_{j=a+1}^{m} \lambda_{j}^{i}, h_{0}=1-\left(\frac{2 \theta_{1} \theta_{3}}{3 \theta_{2}^{2}}\right)$ and $C_{\alpha}$ is the value of the normal distribution with $\alpha$ level of significance.

\section{DESIGN OF CONTROLLER IN SUBSPACE}

PCA model can be determined from process data according to section (2). The process data taken for determination of PCA model should be collected when process operated at normal or desired operating point. If any changes occur in operating conditions, this change cannot reflect in static PCA model. Projection of the steady state values of control variables onto PCA model (loading matrix) provides scores set-points as per equation (5). The actual set-points region gets transformed into projected set-points region. All these operations so far have been executed offline. From this point onwards, every operation becomes online. New measurement vector of current process is collected at time instant $k$ and is projected onto established PCA model to obtain current scores as shown in equation (6). Equation (7) computes the variation between the projected set-points and current scores and is designated as subspace errors. Using sum of squares of error (eq.8), proportional control law is developed in equation (9) to calculate manipulate variable action at instant $k$. The manipulated variable in subspace brings process to the required operation region (steady state region) optimizing implicitly the gain, $K c$ using Genetic algorithm.

$$
\begin{aligned}
& t_{s p}(k)_{1 \times a}=x_{\text {setpoints }_{1 \times m}}(k)\left(P_{m \times a}\left(P_{a \times m}{ }^{T} P_{m \times a}\right)^{-1}\right) \\
& t_{\text {new }}(k)_{1 \times a}=x_{\text {new }_{1 \times m}}(k) P_{m \times a}\left(P_{a \times m}{ }^{T} P_{m \times a}\right)^{-1} \\
& e_{\text {subsp }}(k)_{1 \times a}=t_{s p}(k)-t_{\text {new }}(k) \\
& \operatorname{sse}(k)_{1 \times 1}=e_{\text {subsp }}(k)_{1 \times a} e_{\text {subsp }}(k)_{a \times 1}{ }^{T} \\
& u(k)_{1 \times 1}=u_{s}+K c * \operatorname{sse}(k)_{1 \times 1}
\end{aligned}
$$

Where $a$ is largest number of principal components.

\section{MATHEMATICAL MODEL OF YEAST FERMENTATION BIOREACTOR}

Fermenting sugars with yeast is one of important processes used for ethanol production. Fig. 2 illustrates ethanol production by yeast fermentation bioreactor with constant substrate inflow and outflow [24]. The reaction volume inside the bioreactor is maintained constant. Modeling of bioreactor is similar to continuous stirred tank with constant reaction volume.

Initially biomass solution, which is suspension of yeast, is fed to the bioreactor. Since the process is carried out in the presence of oxygen, a baker's yeast (saccharomyces cerevisiae) is used. There is continuous supply of substrate i.e. solution of glucose which feeds the microorganisms to the bioreactor. For the formation of coenzymes, inorganic salts are added together with biomass. The equilibrium concentration of oxygen in the liquid phase is influenced by inorganic salts because of the salting-out effect. The effect of dissolved inorganic salts as well as temperature on the equilibrium concentration of oxygen in the liquid phase is explained by equations (10) to (29). Yeast hydrolyses glucose into ethanol and carbon dioxide. The contents of the reactor are biomass, substrate and product. The product is continuously withdrawn along with biomass and substrate.

The following equations are used to calculate molar concentrations and ionic strength of ions in the reaction medium.

$$
\begin{aligned}
& C_{\mathrm{Na}}=\frac{m_{\mathrm{NaCl}}}{M_{\mathrm{NaCl}}} \frac{M_{\mathrm{Na}}}{V} \\
& C_{\mathrm{Ca}}=\frac{m_{\mathrm{CaCO}_{3}}}{M_{\mathrm{CaCO}_{3}}} \frac{M_{\mathrm{Ca}}}{V} \\
& C_{\mathrm{Mg}}=\frac{m_{\mathrm{MgCl}_{2}}}{M_{\mathrm{MgCl}}} \frac{M_{\mathrm{Mg}}}{V} \\
& C_{\mathrm{Cl}}=\left[\frac{m_{\mathrm{NaCl}}}{M_{\mathrm{NaCl}}}+2 \frac{m_{\mathrm{MgCl}_{2}}}{M_{\mathrm{MgCl}_{2}}}\right] \frac{M_{\mathrm{Cl}}}{V} \\
& C_{\mathrm{CO}_{3}}=\frac{m_{\mathrm{CaCO}_{3}}}{M_{\mathrm{CaCO}_{3}}} \frac{M_{\mathrm{CO}_{3}}}{V} \\
& C_{\mathrm{H}}=10^{-p H} \\
& C_{\mathrm{OH}}=10^{-(14-p H)} \\
& I_{\mathrm{Na}}=0.5 C_{\mathrm{Na}}(1)^{2} \\
& I_{\mathrm{Ca}}=0.5 C_{\mathrm{Ca}}(2)^{2} \\
& I_{\mathrm{Mg}}=0.5 C_{\mathrm{Mg}}(2)^{2} \\
& I_{C l}=0.5 C_{\mathrm{Ca}}(-1)^{2} \\
& I_{\mathrm{CO}}=0.5 C_{\mathrm{CO}}(-2)^{2} \\
& I_{H}=0.5 C_{\mathrm{H}}(1)^{2} \\
& I_{O H}=0.5 C_{\mathrm{OH}}(-1)^{2}
\end{aligned}
$$

The global effect of the ionic strengths is given by equation (24).

$\sum H_{i} I_{i}=H_{N a} I_{N a}+H_{C a} I_{C a}+H_{M g} I_{M g}+H_{C l} I_{C l}+H_{C O_{3}} I_{C O_{3}}+$ $H_{H} I_{H}+H_{O H} I_{O H}$

Equation (25) gives the dependence of equilibrium concentration of oxygen with temperature in distilled water.

$C_{O_{2, o}}^{*}=14.6-0.3943 T_{r}+0.007714 T_{r}^{2}-0.0000646 T_{r}^{3}$

Equilibrium concentration of oxygen in liquid phase is obtained from the following Setchenov type equation.

$C_{O_{2,}}^{*}=C_{O_{2, o}}^{*} 10^{-\sum H_{i} I_{i}}$ 


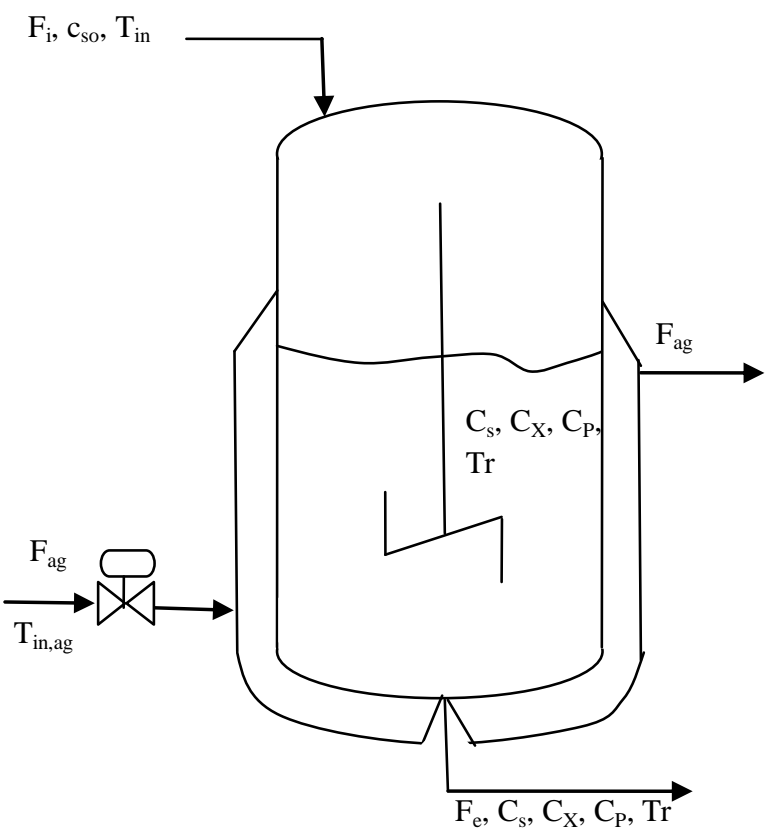

Inputs

Glucose inlet flow rate, $F_{i}$

Glucose inlet concentration, $C_{S, \text { in }}$

Glucose inlet temperature, $T_{\text {in }}$

Coolant inlet flow rate, $F_{a g}$

Coolant inlet temperature, $T_{i n, a g}$

$\underline{\text { States }}$

Substrate outlet flow rate, $F_{i}$

Biomass concentration, $C_{X}$

Glucose concentration, $C_{S}$

Ethanol concentration, $C_{P}$

Reactor temperature, $T_{r}$

Coolant outlet temperature, $T_{a g}$

Output

Reactor temperature, $T_{r}$

Manipulate variable

Coolant flow rate, $F_{a g}$

Fig 2: Bioreactor

The equation (27) given below relates the mass transfer coefficient of oxygen with temperature.

$\left(k_{1} a\right)=\left(k_{1} a\right)_{0}(1.204)^{T_{r}-20}$

The rate of oxygen consumption is

$r_{O_{2}}=\mu_{O_{2}} \frac{1}{Y_{O_{2}}} c_{X} \frac{c_{O_{2}}}{K_{O_{2}}+c_{O_{2}}}$

Equation (29) gives the expression of the maximum specific growth rate.

$\mu_{X}=A_{1} e^{\frac{-E a_{1}}{R(T r+273)}}-A_{2} e^{\frac{-E a_{2}}{R\left(T_{r}+273\right)}}$

The nonlinear dynamic model containing ordinary differential equations from (30) to (36) represents the actual process. There are five input variables; substrate feed concentration $\left(C_{S, \text { in }}\right)$, substrate inlet flow rate $\left(F_{I}\right)$, substrate inlet temperature $\left(T_{i n}\right)$, coolant inlet flow rate $\left(F_{a g}\right)$ and coolant inlet temperature $\left(T_{\text {in,ag }}\right)$, and six states; biomass concentration $\left(C_{X}\right)$, substrate concentration $\left(C_{S}\right)$, ethanol concentration $\left(C_{P}\right)$ and dissolved oxygen concentration $\left(C_{O_{2}}\right)$, reactor temperature $\left(T_{r}\right)$ and cooling jacket temperature $\left(T_{a g}\right)$. There is constant inflow and outflow of substrate so that the volume of reaction medium is not considered as state. The values of parameters used in the model are provided in Table 1. Table 2 presents the values of input and steady state values.

$\frac{d V}{d t}=F_{i}-F_{e}$

$\frac{d c_{X}}{d t}=\mu_{X} c_{X}\left(\frac{c_{S}}{K_{S}+c_{S}}\right) e^{-K_{P} C_{P}}-\frac{F_{e}}{V} c_{X}$ $\frac{d c_{P}}{d t}=\mu_{P} c_{X}\left(\frac{c_{S}}{K_{S 1}+c_{S}}\right) e^{-K_{P 1} C_{P}}-\frac{F_{e}}{V} c_{P}$

$\frac{d c_{S}}{d t}=\frac{1}{R_{S X}} \mu_{X} c_{X}\left(\frac{c_{S}}{K_{S}+c_{S}}\right) e^{-K_{P} C_{P}}-\frac{1}{R_{S P}} \mu_{P} c_{X}\left(\frac{c_{S}}{K_{S 1}+c_{S}}\right) e^{-K_{P 1} c_{P}}+$

$\frac{F_{i}}{V} c_{S, i n}-\frac{F_{e}}{V} c_{S}$

$\frac{d c_{O_{2}}}{d t}=\left(k_{1} a\right)\left(c_{O_{2}}^{*}-c_{O_{2}}\right)-r_{O_{2}}-\frac{F_{e}}{V} c_{O_{2}}$

$\frac{d T_{r}}{d t}=\frac{F_{i}}{V}\left(T_{\text {in }}+273\right)-\frac{F_{e}}{V}\left(T_{r}+273\right)+\frac{r_{O_{2}} \Delta H_{r}}{32 \rho_{r} C_{\text {heat }, r}}+$

$\frac{K_{T} A_{T}\left(T_{r}-T_{a g}\right)}{V_{j} \rho_{a g} C_{\text {heat }, a g}}$

$\frac{d T_{a g}}{d t}=\frac{F_{a g}}{V_{j}}\left(T_{i n, a g}-T_{a g}\right)+\frac{K_{T} A_{T}\left(T_{r}-T_{a g}\right)}{V_{j} \rho_{a g} C_{\text {heat }, a g}}$

\section{Table 1: Parameters used in the process model}

\begin{tabular}{lll}
\hline$A_{1}=9.5 \times 10^{8}$ & $H_{C l}=0.844$ & $R_{S P}=0.435$ \\
$A_{2}=2.55 \times 10^{33}$ & $H_{C_{3}}=0.485$ & $R_{S X}=0.607$ \\
$A_{T}=1 m^{2}$ & $H_{H O}=0.941$ & $V=1000 \mathrm{~L}$ \\
$C_{h e a t, a g}=4.18 \mathrm{~J}$ & $\left(k_{l} a\right)_{0}=38 \mathrm{~h}^{-1}$ & $V_{j}=50 \mathrm{~L}$ \\
$\mathrm{~g}^{-1} \mathrm{~K}^{-1}$ & $K_{O_{2}}=8.86 \mathrm{mg} / 1$ & $Y_{O_{2}}=0.970$ \\
$C_{\text {heat }, r}=4.18 \mathrm{~J} \mathrm{~g}$ & $K_{P}=0.139 \mathrm{~g} / 1$ & $\mathrm{mg} / \mathrm{mg}$ \\
${ }^{1} \mathrm{~K}^{-1}$ & $K_{P 1}=0.070 \mathrm{~g} / 1$ & $\Delta H_{r}=518$ \\
$E_{a 1}=55000$ & $K_{S}=1.030 \mathrm{~g} / \mathrm{l}$ & $\mathrm{KJ} / \mathrm{mol} \mathrm{O}_{2}$ \\
$\mathrm{~J} / \mathrm{mol}$ & $K_{S 1}=1.680 \mathrm{~g} / 1$ & $\mu_{O_{2}}=0.5 \mathrm{~h}^{-1}$ \\
$E_{a 2}=220000$ & $K_{T}=3.6 \times 10^{5}$ & $\mu_{P}=1.790 \mathrm{~h}^{-1}$ \\
$\mathrm{~J} / \mathrm{mol}$ & $\mathrm{Jh}^{-1} \mathrm{~m}^{-2} \mathrm{~K}^{-1}$ & $\rho_{a g}=1000 \mathrm{~g} / 1$ \\
$H_{N a}=-0.550$ & $m_{N_{a C l}}=500 \mathrm{~g}$ & $\rho_{r}=1080 \mathrm{~g} / 1$ \\
$H_{C a}=-0.303$ & $m_{\mathrm{CaC}_{O_{3}}}=100 \mathrm{~g}$ & $P_{H}=6$ \\
$H_{M g}=-0.314$ & $m_{M l_{2}}=100 \mathrm{~g}$ & $H_{H}=-0.774$ \\
\hline
\end{tabular}


Table 2: Values of process variables

\begin{tabular}{cc}
\hline Inputs & States \\
\hline$F_{I}=51 \mathrm{Lh}^{-1}$ & $C_{X}=0.8539 \mathrm{~g} / \mathrm{l}$ \\
$F_{e}=51 \mathrm{Lh}^{-1}$ & $C_{P}=12.1722 \mathrm{~g} / 1$ \\
$T_{i n}=25^{\circ} \mathrm{C}$ & $C_{S}=33.42 \mathrm{~g} / 1$ \\
$C_{S, i n}=60 \mathrm{~g} / \mathrm{l}$ & $C_{O_{2}}=4.5939 \mathrm{~g} / 1$ \\
$T_{i n, a g}=15^{\circ} \mathrm{C}$ & $T_{r}=28.7188^{\circ} \mathrm{C}$ \\
$F_{a g}=18 \mathrm{Lh}^{-1}$ & $T_{a g}=26.3472^{\circ} \mathrm{C}$ \\
\hline
\end{tabular}

\section{ANALYSIS OF DYNAMIC BEHAVIOR OF BIOREACTOR}

The nonlinear model presented in previous section describes yeast fermentation process. The process was simulated under SIMULINK environment. The major task of bioreactor is to achieve steady state ethanol concentration inferentially even in the presence of external influences by controlling reactor temperature; a secondary measurement. The coolant inlet flow rate can serve as manipulated variable to control reactor temperature. The disturbance inputs considered are substrate inlet temperature and substrate inlet concentration. The transient behaviors of the bioreactor have been studied in the presence of various disturbances. Fig. 3 presents the responses of reactor temperature and ethanol concentration to step change in substrate inlet temperature from 25 to $30{ }^{\circ} \mathrm{C}$. Considerable variation can be seen in reactor temperature and ethanol concentration. When substrate inlet concentration was changed from 60 to $65 \mathrm{~g} / \mathrm{l}$, the reactor temperature did not shift from its steady state whereas the product concentration was slightly deviated from steady state. The response of the process to step change in substrate inlet concentration is depicted in fig. 4. This study reveals that only the substrate inlet temperature can be a considerable disturbance. The remaining inputs along with substrate inlet concentration were kept constant at their respective steady states. The control objective of multivariable system is reduced to a SISO control problem since there is only one control variable, $T_{r}$, and one manipulate variable, $F_{a g}$.
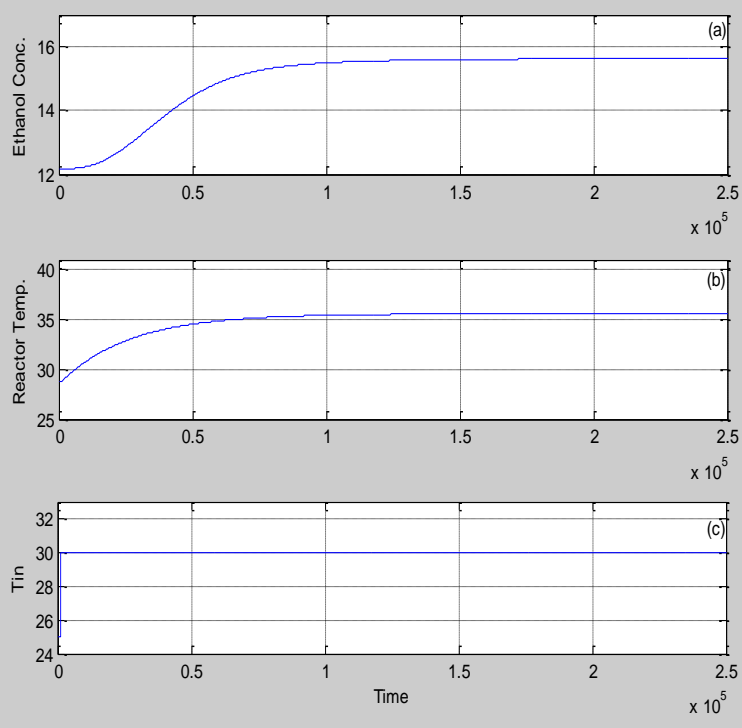

Fig 3: Response of bioreactor to step change in substrate inlet temperature.

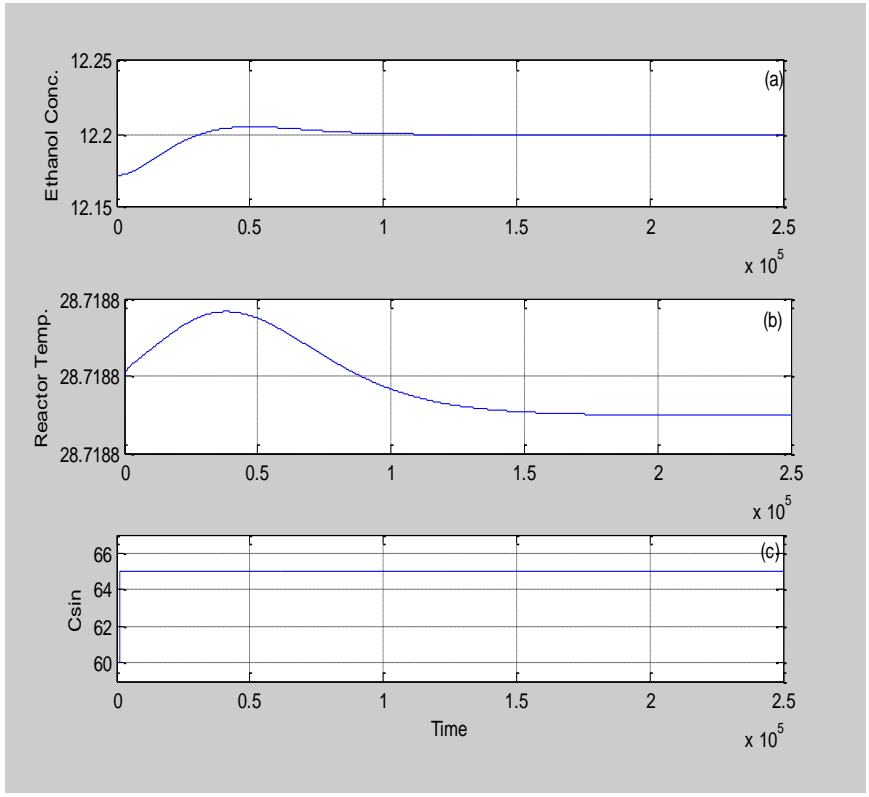

Fig 4: Response of bioreactor to step change in substrate inlet concentration.

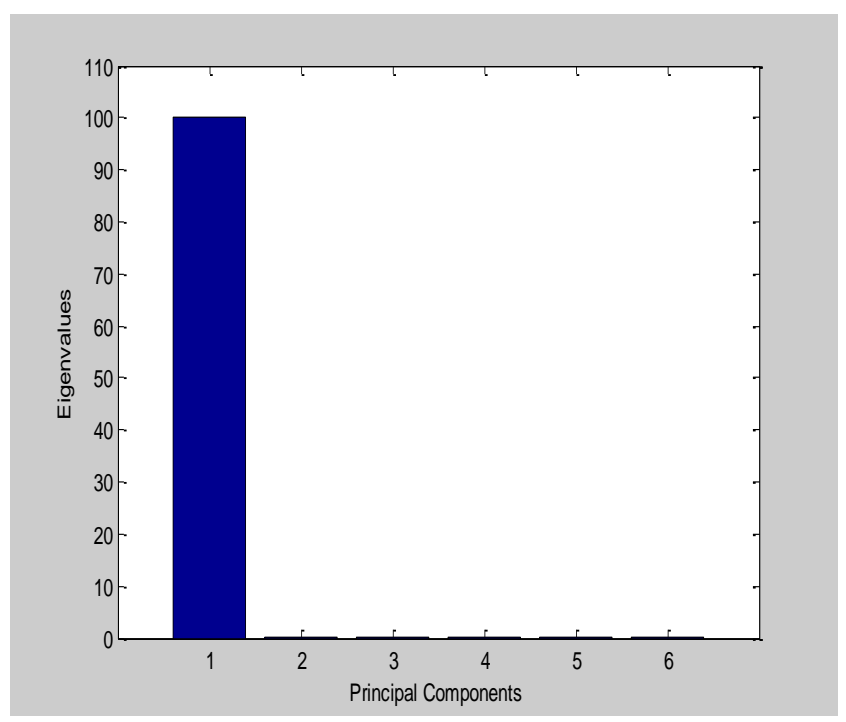

Fig 5: Selection of Principal Components using Cumulative Percent Variance

\section{IDENTIFICATION OF BIOREACTOR PROCESS IN SUBSPACE}

Process data, $X$, was collected by simulating the process at normal operating condition. The data matrix, $X$ contains 100001 samples of 6 process variables. This data was scaled to zero mean and unit variance. Static PCA model was determined from scaled data. Cumulative Percent Variance (CPV) method was used to find the largest number of principal components. Fig. 5 shows that first principal component $\quad(a=1$, projected biomass concentration $)$ describes $99.9 \%$ of variation in the process data. The remaining directions or principal components were 
unimportant. Therefore biomass concentration inside the reactor was good enough to represent the actual process in subspace. The loading matrix of size $6 \times 1$ was calculated and this could represent fermentation process in low dimensional space.

\section{RESULTS AND DISCUSSIONS}

The PCA decomposition of $(100001 \times 6)$ process data matrix resulted in $(6 \times 6)$ eigenvector matrix and the Cumulative Percent Variance analysis (Fig.5) established it ultimately as $(6 \times 1)$ eigenvector matrix. Original process data matrix transformed in to a projected process matrix/score matrix $(100001 \times 1)$ on projection of process matrix upon resulted eigenvector. As a consequence of PCA decomposition the Yeast fermentation process essentially became a SISO process from the perspective of control system design.

The proposed statistical SISO controller was used to control yeast fermentation bioreactor. The statistical control system tries to reduce discrepancy in ethanol concentration by controlling reactor temperature while the coolant flow rate, $F_{a g}$ is maintained at its steady state value. To ensure controller's performance in the presence of external influences, positive and negative step changes in disturbance input are considered. Fig. 6 depicts the responses of bioreactor to positive step change in substrate inlet temperature, $T_{i n}$, from 25 to $30{ }^{\circ} \mathrm{C}$. The statistical controller avoided influence of disturbance on process. Reactor temperature is oscillating with decreasing amplitude in the vicinity of steady state until $t=378^{\text {th }}$ instant and then reaches steady state with an offset of $2 \times$ $10^{-4}$. It can also be observed that ethanol concentration acquires steady state with negligible offset. Step change in substrate inlet temperature, $T_{i n}$, from 25 to $20{ }^{\circ} \mathrm{C}$ caused the process variables to deviate slightly from their respective steady states as shown in fig. 7. But there are oscillations in reactor temperature for relatively longer time (until $t=800$ ). Pseudo random noise was added to process measurements. The statistical controller is tested in the event of noise on measurements. The effect of noise is nullified and both reactor temperature and product concentration achieve steady state with large settling time as illustrated in fig. 8. Table 3 presents the offsets that were obtained during the presence of disturbance and noise.

$Q$-statistic (SPE) of process measurements recorded during each of the positive step, negative stpe in substrate inlet temperature, $T_{\text {in }}$ and after imposition of noise over the measurements of $T_{\text {in }}$ were computed and plotted in fig. 9. Qstatistic of the three aforesaid opeating regions remained below $Q$-threshold that confirms that in the face of disturbances and noise the process could be held to the steady state condition using the controller designed.

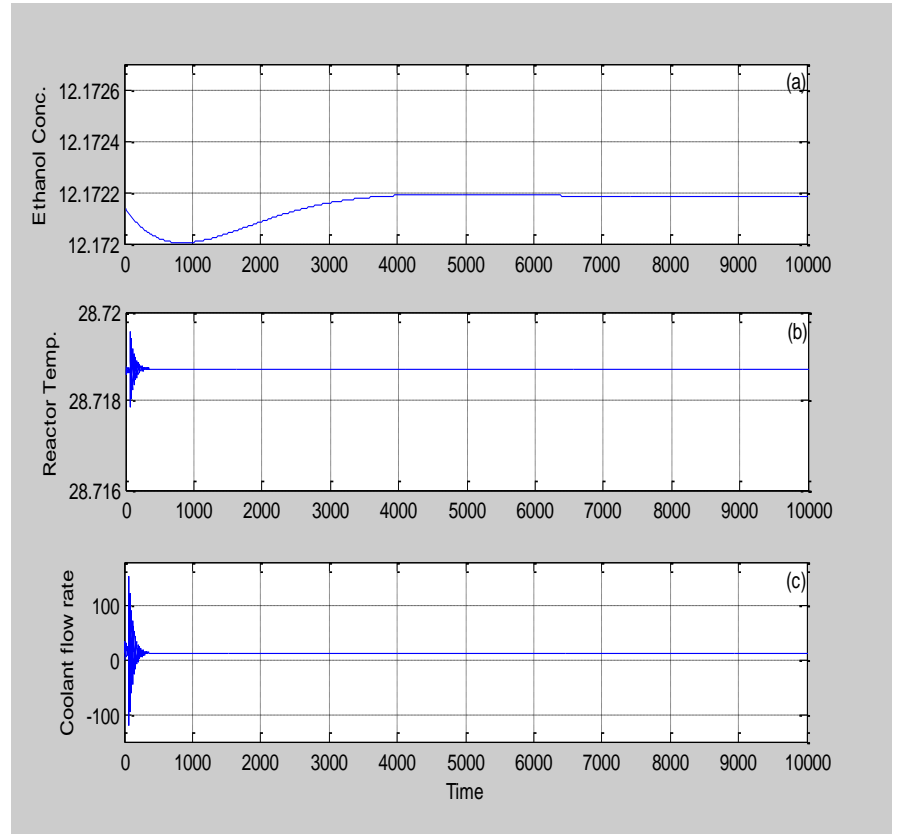

Fig 6: Response of statistical control system to positive unit step change in substrate inlet temperature

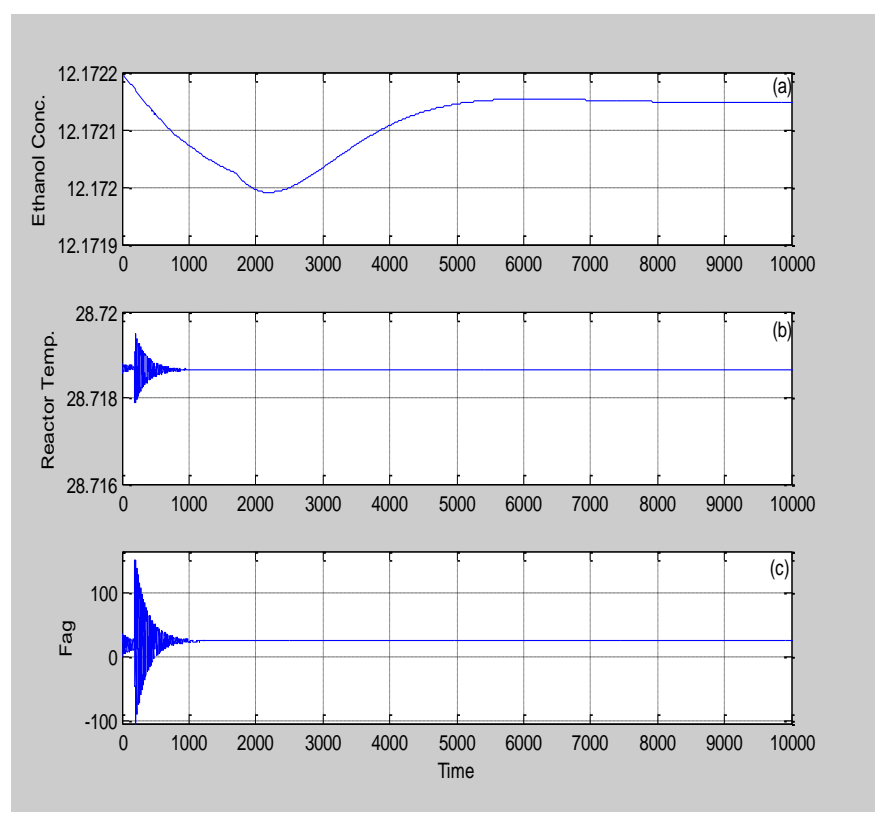

Fig 7: Response of statistical control system to negative step change in substrate inlet temperature

Table 3: Offset in different modes of operation

\begin{tabular}{|c|c|c|}
\hline Type of disturbance & $\begin{array}{c}\text { Ethanol } \\
\text { Concentration }\end{array}$ & $\begin{array}{c}\text { Reactor } \\
\text { Temperature }\end{array}$ \\
\hline $\begin{array}{c}\text { Positive step } \\
\text { change in } T_{\text {in }}\end{array}$ & 0.00009 & 0.0002 \\
\hline $\begin{array}{l}\text { Negative step } \\
\text { change in } T_{\text {in }}\end{array}$ & 0.00007 & 0.0002 \\
\hline $\begin{array}{c}\text { Noise in } \\
\text { measurements }\end{array}$ & 0.00008 & 0 \\
\hline
\end{tabular}





Fig 8: Response of statistical control system to noise in measurements

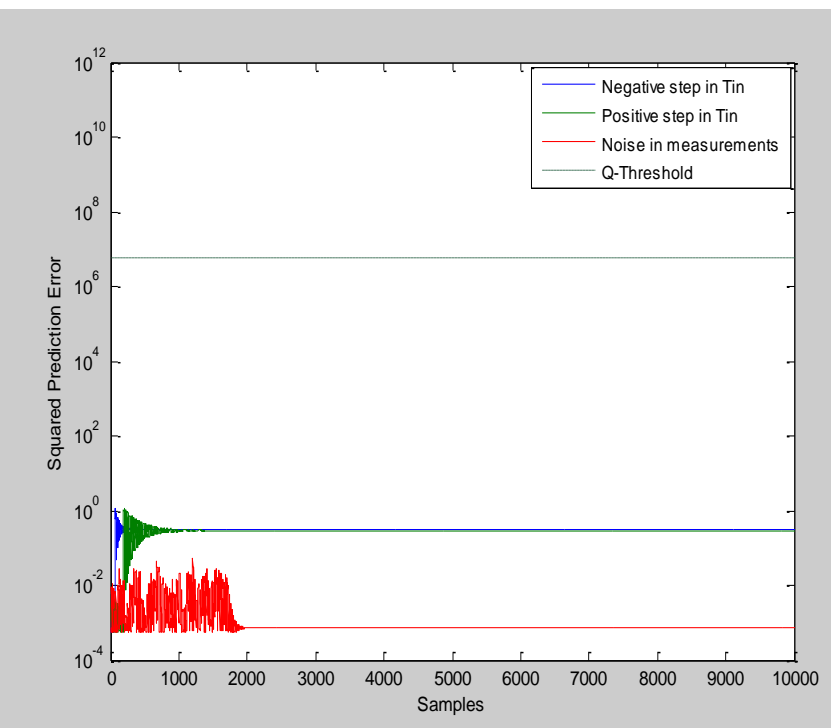

Fig 9: Squared prediction error of three disturbance modes.

\section{CONCLUSIONS}

In the present study, the PCA based controller was developed in subspace to control temperature of the Yeast fermentation bioreactor, hence the product ethanol concentration in the face of disturbance in substrate inlet temperature and noise. $Q$ statistic (SPE) of the process also confirmed the suitability of the developed controller. The SISO controller designed actually controlled a MIMO process in an inferential fashion.

\section{REFERENCES}

[1] G. P. Reddy, M. Chidambaram, "Nonlinear control of bioreactors with input multiplicities", Bioprocess Eng., Vol. 11, (1994), pp: 97-100.
[2] S. N. Jyothi, M. Chidambaram, "Nonlinear feedforward control of bioreactors with input multiplicities", Bioproc. Biosyst. Eng., Vol. 24, (2001), pp: 123-129

[3] T. K. Radhakrishnan, S. Sundaram, M. Chidambaram, "Non-linear control of continuous bioreactors", Bioprocess Eng., Vol. 20, (1999), pp: 173-178

[4] M. Galluzzo, B. Cosenza, A. Matharu, "Control of a nonlinear continuous bioreactor with bifurcation by a type-2 fuzzy logic controller", Comput. Chem. Eng., Vol. 32 (12), (2008), pp: 2986-2993

[5] D. Constantino, D. Pierre, F. Claude, L. Philippe, S. Marc, "Adaptive predictive control of dissolved oxygen concentration in a laboratory-scale bioreactor", J Biotechnol., Vol. 43, (1995), pp: 21-32

[6] H. J. Tham, K. B. Ramachandran, M. A. Hussain, "Sliding Mode Control for a Continuous Bioreactor", Chem. Biochem. Eng., Q., Vol. 17 (4), (2003), pp: $267-$ 275

[7] S. Ramaswamy, T. J. Cutright, H. K. Qammar, "Control of a continuous bioreactor using model predictive control", Process Biochem., Vol. 40, (2005), pp: 2763 2770

[8] G-Y. Zhu, A. Zamamiri, M. A. Henson, M. A. Hjortso, "Model predictive control of continuous yeast bioreactors using cell population balance models", Chem. Eng. Sci., Vol. 55, (2000), pp: 6155-6167

[9] K. N. Zoltan, "Model based control of a yeast fermentation bioreactor using optimally designed artificial neural networks", Chem. Eng. J., Vol. 127 (2007), pp: 95-109

[10] J. E. Jackson, “A User's Guide to Principal Components", Wiley, New York, (2003).

[11] R. Takros, M. Gerigk, H. Paschold, C. Wandrey, "Principal Component Analysis for Microbial LPhenylalanine Production”, Bioproc. Biosyst. Eng., Vol. 24, (2001), pp: 93-99.

[12] J. M. Escano, F. Dorado, "PCA based Pressure control of a Gas Mixing Chamber", IEEE Conference on Emerging Technologies \& Factory Automation, Mallorca, Spain, (2009).

[13] J. E. Jackso, G. Mudholkar, "Control procedures for residuals associated with principal component analysis", Technometrics, Vol. 21, (1979), pp: 341-349.

[14] J. Kresta, J. F. MacGregor, T. E. Marlin, "Multivariate statistical monitoring of process operating performance", Can. J. Chem., Vol. 69 (1), (1991), pp: 35-47

[15] P. Nomikos, J. F. MacGregor, "Monitoring Batch Processes using Multiway Principal Component Analysis", AIChE J., Vol. 40(8), (1994), pp: 1361-1375

[16] M. J. Piovoso, K. A. Kosanovich, P. K. Pearson, "Monitoring process performance in real-time", In Proc. of 1991 ACC Boston, Massachusetts, (1991), pp: 721724

[17] M. J. Piovoso, K. A. Kosanovich, "Applications of Multivariate Statistical Methods to Process Monitoring and Controller Design", Int. J. Control, Vol. 59 (3), (1994), pp: 743-765. 
[18] G. Chen, T. J. McAvoyy, M. J. Piovoso, "A multivariate statistical controller for on-line quality improvement", J. Proc. Cont., Vol. 8 (2), pp: 139-149

[19] X. Liu, X. Chen, W. Wu, Y. Zhang, "Process control based on principal component analysis for maize drying", Food Control, Vol. 17, (2006), pp: 894-899

[20] L. B. Palma, F. V. Coito, P. S. Gil, R. Neves-Silva, "Process Control based on PCA Models", $15^{\text {th }}$ IEEE Int. Conf. on Emerging Technologies and Factory Automation, Univ. of the Basque Country, Bilbao, Spain, (2010).

[21] L. B. Palma, F. V. Coito, P. S. Gil, R. Neves-Silva, "Design of Adaptive PCA Controllers for SISO
Systems", 18th IFAC World Congress Milano, Italy, (2011)

[22] S. L. Shah, R. Miller, H. Takada, K. Morinaga, T. Satou, "Modelling and control of a tubular reactor: A PCA based approach", Fifth IFAC symposium on dynamics and control of process systems, Corfu, Greece, (1998), pp: 17-22.

[23] K. Akamatsu, S. Lakshminarayanan, H. Manako, H. Takada, T.Satou, S. Shah, "Data-based control of an industrial tubular reactor", Control Eng. Pract., Vol. 8, (2000), pp: 783-790.

[24] S. A. Paul, K. N. Zoltan, V. C. Mircea, I. L. Arpad, "Model Based Control: Case Studies in Process Engineering", Wiley-VCH, Weinheim, (2006). 